\title{
Umbilical myiasis with sepsis in a neonate
}

\author{
Monojit Mondal', Tanmoy Biswas', Nayan Banerji', Sayan Bose', Biswajit Biswas', Pijush Kanti Mandal² \\ ${ }^{1}$ Department of Pediatric Medicine, Burdwan Medical College, Burdwan, ${ }^{2}$ Department of Medicine, ESI PGIMSR, Maniktala, Kolkata, India
}

\section{A B S T R A C T}

Myiasis is the invasion of host's tissues by the larval stage (maggot) of non-biting flies. It usually infects domestic and wild animals, but sometimes also affects human and is commonly found in the tropical and subtropical areas. Umbilical myiasis in the neonatal period associated with sepsis is a rare occurrence with few reported cases in the literature. We report a case of a 20-days-old neonate from a rural area of West Bengal, India, presented with neonatal sepsis due to umbilical myiasis caused by larval form of blow fly (Chrysomya megacephala).

Key words: Myiasis, Neonate, Umbilical, Chrysomya

\section{INTRODUCTION}

Myiasis is defined as the invasion of live mammalian tissue by the larvae of dipteran flies which feed on the host's dead or living tissue, body fluids or ingested food, commonly seen in the tropics and subtropics. ${ }^{1-3}$ Myiasis can be classified according to the anatomic site of infestation (i.e. aural myiasis, ophthalmomyiasis, or cutaneous myiasis) or on the basis of the clinical syndrome (i.e. furuncular cutaneous myiasis, migratory cutaneous myiasis, or wound myiasis). ${ }^{4}$ Although myiasis is mainly a disease of animals but humans may be affected sometimes when they are reared in poor hygienic conditions. Umbilical cord myiasis with sepsis in the human neonatal period is a very rare occurrence and almost exclusively found in neotropic areas. ${ }^{5,6}$

\section{CASE REPORT}

\section{History}

A 20 days old female neonate from an rural area of West Bengal (India), born out of non-consanguineous marriage belonging to a poor socioeconomic family presented with history of something coming out from the umbilicus. This baby was delivered vaginally at a district hospital of West Bengal (India). Antenatal, intranatal and postnatal periods were uneventful and both mother and baby were discharged from hospital on next day.
Access this article online

Website:

http://nepjol.info/index.php/AJMS

\section{On examination}

Neonate weighed $2.25 \mathrm{Kg}$, cry, reflex and activities were average, the pulse rate was 168 per minute, respirations 46 breaths $/ \mathrm{min}$, temperature $39.1^{\circ} \mathrm{C}$, have a flat anterior fontanelle, mild hepato-splenomegaly and normal cardio-respiratory system findings. The cord was absent at umbilicus and on close observation movements of some live cylindrical white maggots were noted at the base of the umbilicus (Figure 1). Several maggots were coming out of umbilicus following instillation of ether (repellent).

\section{Investigations}

Revealed sepsis screen positive, blood culture and culture from the umbilical swab shows growth of Staphylococcus aureus, ultrasound examination was done and showed maggots and umbilical cellulitis present. Following removal, the maggots were preserved in $80 \%$ of alcohol and sent for species identification which reveals Chrysomya megacephala.

\section{Treatment}

Maintenance of hygiene, intravenous administration of Cefotaxime $(150 \mathrm{mg} / \mathrm{kg}$ of body weight per day) and Amikacin (15 mg/kg per day) for ten days along with topical antibiotic ointment.

\section{DISCUSSION}

Umbilical myiasis, a type of cutaneous tissue myiasis, is usually produced by larvae of flies (Diptera) of various 


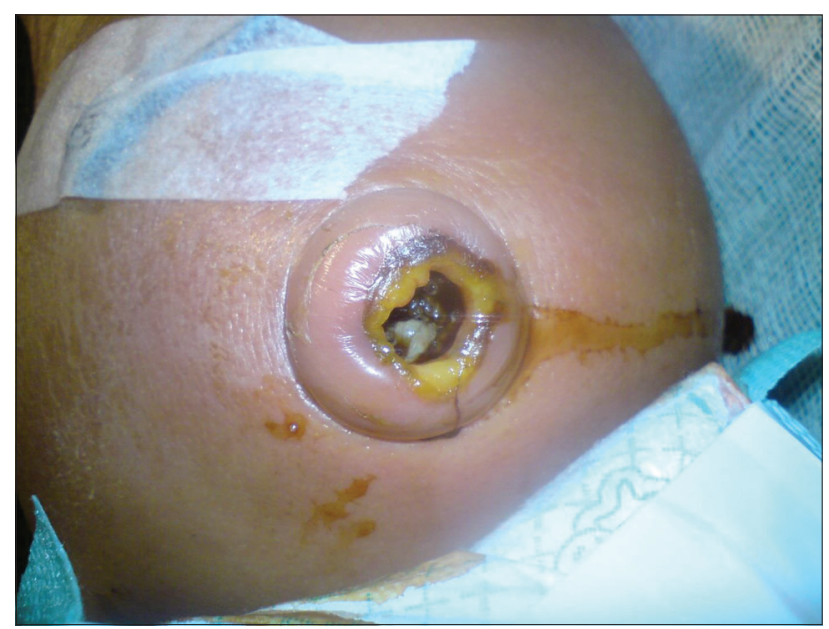

Figure 1: White maggots at the base of the umbilicus

kinds which invade the live mammalian tissue, feed on the host's dead or living tissue, body fluids or ingested food. The occurrence of human myiasis has been linked to humid and warm climates that favour the breeding of flies. Epizootics in livestock, marginal housing, poor disposal of refuse, and undernutrition also are important factors in the development of human myiasis. ${ }^{1-5}$ In umbilical myiasis the fly lays eggs on dry skin and the larvae subsequently invade the wound. Larvae grow rapidly and reach maturity in 4-8 days. ${ }^{7}$ Typical larvae are cylindrical, whitish, segmented, legless, and headless, ranging in length from 1 to $30 \mathrm{~mm} .{ }^{8}$ The larvae are removed from the affected site of the host by irrigation, manipulation or surgery. The larvae should be preserved in $80 \%$ alcohol for identification. Third stage larva is ideal for species identification. ${ }^{9}$ In our case, the larvae were diagnosed as Chrysomya megacephala, a member of Chrysomya genus in the Calliphoridae family of blowflies. ${ }^{10}$ The macroscopic view of the larvae that crawled out of our patient's umbilicus is shown in Figure 2.

In the Indian population (especially rural or urban slum area) defaecating in open air is a common practice. The fly is attracted by faeces and lays eggs on them. After landing on faeces it lands commonly on human foods and on very rare occasion on open human wounds or on umbilicus of a newborn. ${ }^{10}$ It may be the same occurrence in our case. The prevention of human myiasis requires good wound care, adequate personal hygiene, screening to protect against flies, and the prevention of myiasis in domestic animals. Removal of maggots, use of local antiseptics, and systemic antibiotics for combating secondary infections have been recommended as treatment options in neonatal myiasis. In our case the patient was given proper antibiotics as per sensitivity and larvae were removed by using ether in the

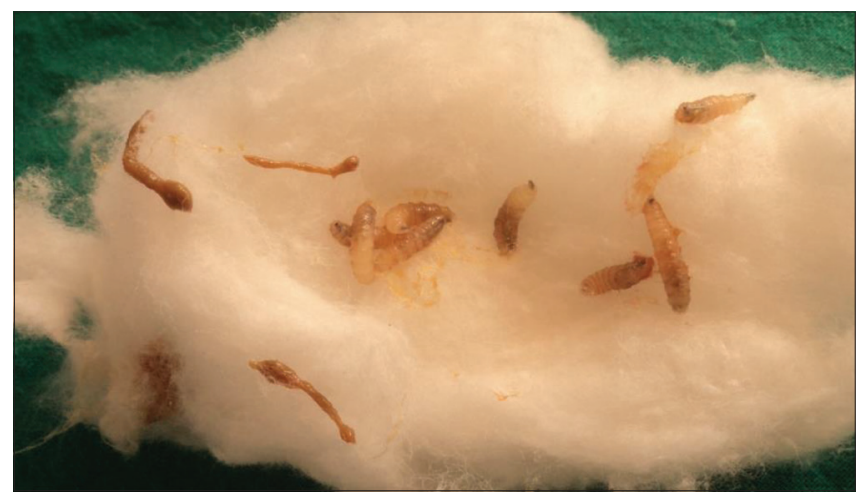

Figure 2: The macroscopic view of the larvae

hospital. After proper management findings resolved with no residual effects. So once the diagnosis has been made, the treatment is usually straightforward and uncomplicated.

\section{CONCLUSION}

The importance of reporting the case is to emphasize the patient's education regarding personal hygiene particularly in neonates and to maintain cleanliness of surrounding area of living.

\section{REFERENCES}

1. Yuca K, Caksen H, Sakin YF, Yuca SA, Kiriş M, Yilmaz H, et al. Aural myiasis in children and literature review. Tohoku J Exp Med 2005;206: 125-130.

2. Noutsis $\mathrm{C}$ and Millikan LE. Myiasis. Dermatol Clin 1994;12: 729-736.

3. Ghosh T, Nayek K, Ghosh N and Ghosh MK. Umbilical myiasis in newborn. Indian Pediatr 2011;48-321-323.

4. Sherman RA. Maggot Therapy Takes Us Back to the Future of Wound Care: New and Improved Maggot Therapy for the $21^{\text {st }}$ Century. J Diabetes Sci Technol 2009; 3(2): 336-344.

5. Duro EA, Mariluis JC and Mulieri PR. Umbilical myiasis in a human newborn. J Perinatol 2007;27:250-251.

6. Macias EG, Graham AJ, Green M and Pierce AW. Cutaneous myiasis in South Texas. N. Engl J Med 1973; 289:1239-1241.

7. Piangjai $\mathrm{S}$, Siriwattanarungsee $\mathrm{S}$, Sukontason $\mathrm{KL}$ and Sukontason K. Morphology and developmental rate of blowflies Chrysomya megacephala and Chrysomya rufifacies in Thailand: application in forensic entomology. Parasitol Res 2008; 102:1207-1216.

8. Miller A. Myiasis. In: Diseases of Children in the Subtropics and Tropics. $4^{\text {th }}$ ed. London, England: ELBS with Edward Arnold London; 1991; 957-959.

9. Cook GC and Zumla A. Medical Acarology and Entomology. Manson's Tropical Disease, 21 $1^{\text {st }}$ edition, Saunders (ELST); 2003. p. 1727-1732.

10. Hammack L. Oviposition by screw-worm flies (Diptera: Calliphoridae) on contact with host fluids. J Econ Entomol. 1991; 84:185-190. 